Global Mental Health

cambridge.org/gmh

\section{Teaching and Learning Commentary}

${ }^{*} \mathrm{DR}, \mathrm{LW}$, and XP contributed equally to this study.

Cite this article: Ren D, Wang L, Pan X, Bai Y, Xu Z (2020). Building a strategic educatorpsychiatrist alliance to support the mental health of students during the outbreak of COVID-19 in China. Global Mental Health 7, e32, 1-3. https://doi.org/10.1017/gmh.2020.27

Received: 30 March 2020

Revised: 14 October 2020

Accepted: 26 October 2020

Authors for correspondence:

Yonghai Bai, E-mail: baiyonghai179@126.com; Zhengmei Xu, E-mail: xuzhengmei@126.com

(c) The Author(s), 2020. Published by Cambridge University Press. This is an Open Access article, distributed under the terms of the Creative Commons Attribution licence (http://creativecommons.org/licenses/by/4.0/), which permits unrestricted re-use, distribution, and reproduction in any medium, provided the original work is properly cited.

\section{CAMBRIDGE} UNIVERSITY PRESS

\title{
Building a strategic educator-psychiatrist alliance to support the mental health of students during the outbreak of COVID-19 in China
}

Ding Ren ${ }^{1, \star}$, Lixia Wang ${ }^{2, \star}$, Xiao $\operatorname{Pan}^{3, \star}$, Yonghai $\mathrm{Bai}^{3}(\mathrm{D})$ and Zhengmei $\mathrm{Xu}^{4}$

\begin{abstract}
${ }^{1}$ Department of Medical Psychology, PLA Navy No. 905 Hospital, Second Military Medical University, Shanghai, 200052, P.R. China; ${ }^{2}$ Shanghai Teacher Training Center, Shanghai, 200234, P.R. China; ${ }^{3}$ Department of Medical Psychology, Shanghai Changzheng Hospital, Second Military Medical University, Shanghai, 200003, P.R. China and ${ }^{4}$ Shanghai Changzheng Hospital, Second Military Medical University, Shanghai, 200003, P.R. China
\end{abstract}

COVID-19, initially identified in Wuhan, Hubei Province, has widely and rapidly spread across China and in many other countries around the world, causing an outbreak of acute infectious pneumonia. The unpredictable future of this epidemic has been exacerbated by myths and misinformation, often driven by erroneous news reports and the public's misunderstanding of health messages, thus causing anxiety in the public. It has been reported that the outbreak of COVID-19 in China has caused public panic and mental health stress (Chen et al., 2020; Duan and Zhu, 2020; Liem et al., 2020; Liu et al., 2020; Yang et al., 2020). Studies have also confirmed that some individuals who have experienced public health emergencies may still have varying degrees of stress disorders, even after the event is over, or after they have been cured and discharged from hospital, indicating that these individuals may need extra care and should not be ignored (Fan et al., 2015).

Since the outbreak of COVID-19, schools have been closed in China. The psychological impact of school closure on students could be significant because they are isolated from the normal school environment. As we know, the school environment not only refers to the physical space, but also includes the emotional and cultural space (Mura et al., 2015). Positive relationship experiences in school, such as peer belonging and teacher support, are significant contributors to students' positive mental health (Oberle et al., 2018). As students are required to study at home, the campus cultural space, the mutual companionship between classmates and the emotional exchange between teachers and students no longer exist. Students are likely to become nervous, anxious, and even panic-stricken (Main et al., 2011). The psychological impact of quarantine may be similar to the effects of sensory deprivation which include confusion, boredom, irritability, and difficulty in concentrating. Indeed, a review on psychological impact of quarantine found that various symptoms such as emotional disturbance, depression, stress, low mood, irritability, insomnia, post-traumatic stress symptoms, anger, and emotional exhaustion had been reported (Brooks et al., 2020). Therefore, it is urgent to assist students to adjust their psychological state and stabilize their mood. Home confinement may also affect students' physical health because they are physically less active and may have irregular sleep patterns and less favorable diets which will result in weight gain and a loss of cardiorespiratory fitness (Wang et al., 2020). Wang and his colleagues analyzed the effects of home confinement on children' physical and mental health during the COVID-19 outbreak, and suggested that the government, non-governmental organizations, the community, school, and caregivers should take timely and sufficient actions to tackle these issues in China (Wang et al., 2020).

The education authorities at all levels responded promptly to the outbreak of COVID-19. Chinese educators are fully aware that the educational function of schools under normal circumstances is largely realized through the school environment, and that the school space is an environment specially created on the basis of the psychological and moral tendencies that affect its members (Mura et al., 2015). They started to provide mental health support at the beginning of the epidemic outbreak, implemented Guidelines of Emergency Psychological Crisis Intervention for COVID-19 Infection and Guidelines for Psychological Assistance Hotline for the Prevention and Control of COVID-19 issued by the National Health Commission (2020), and provided services including psychological support hotlines and online counseling. Among these effective actions, the most valuable and innovative support for students is the establishment of the Education System Epidemic Prevention Alliance, a joint effort between Chinese educators and mental health professionals. This alliance is mainly aimed at elementary school students, junior high school students, and high school students. In Shanghai, the schools that were involved launched quick and effective actions to ensure the mental health of teachers, students and caregivers after the COVID-19 outbreak in November 2019, based on a three-tiered psychological support system (TTPSS) (Fig. 1) 


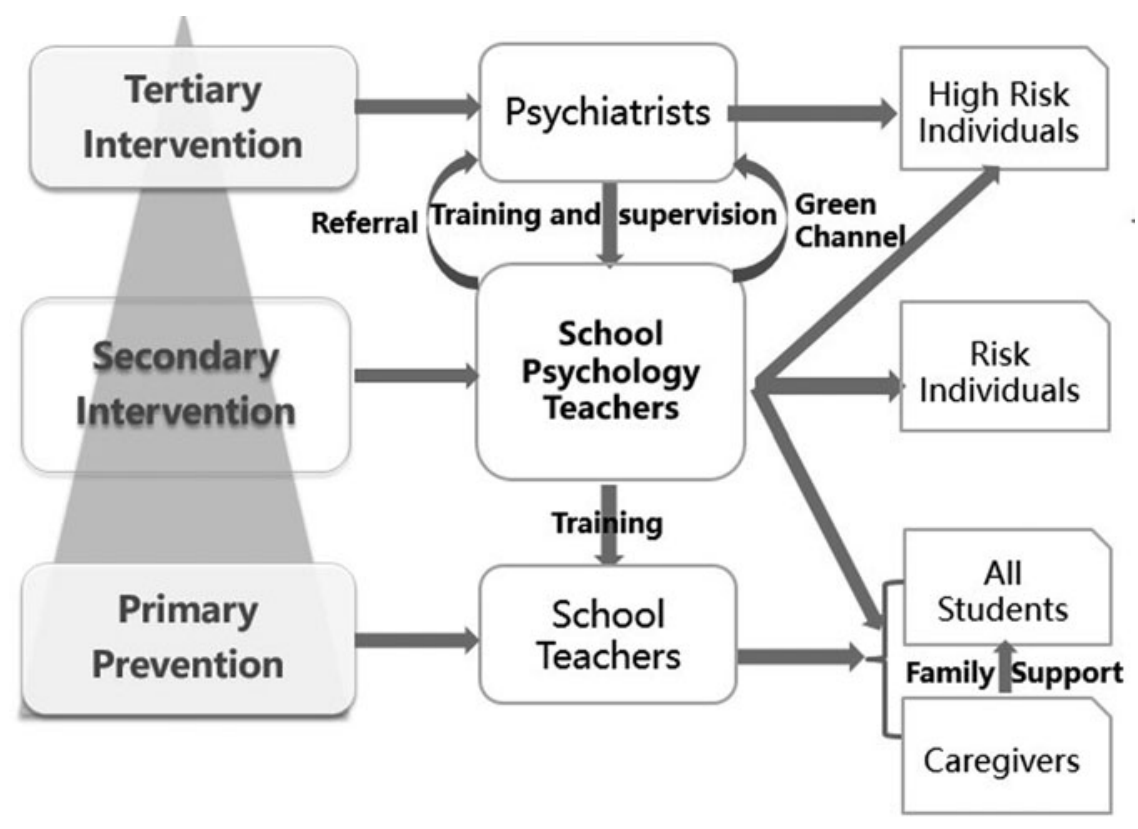

Fig. 1. Three-tiered psychological support system for students and staff.

constructed by the Shanghai Teacher Training Center and the Medical Psychology Department at Shanghai Changzheng Hospital.

The TTPSS mainly addresses mental health issues of students and the professional competency enhancement of school psychology teachers who are responsible for delivering psychology courses and offering psychological counseling at school. The system is based on the Biopsychosocial Model, which provides the basic paradigm for mental health as it is now broadly accepted that illness and health are the result of the interaction of biological, psychological, and social factors (Engel, 1980; Read et al., 2008; Alvarez et al., 2012), and derives from the Tertiary Disease Prevention Model, which includes three categories of prevention, aiming to prevent disease or injury, reduce the impact of disease or injury, and soften the impact of an ongoing illness or injury respectively (Institute for Work \& Health, 2015).

At the primary level, all school teachers are trained by school psychology teachers to obtain the general knowledge of psychology in order to popularize it and education students and caregivers about it. The goal at the primary level is to prevent emotional and behavioral disorders such as anxiety and depression. School teachers give lessons to students and caregivers. The lessons targeted at students include emotional control, psychological resilience improvement, and learning-related anxiety management. The lessons for caregivers include caregiver-child communication and stress management. Thus, the caregivers can provide more beneficial family support to students. The interaction between students through face-to-face communication or social network apps such as DingTalk, WeChat, and QQ will also construct favorable peer support relationships.

At the secondary level, school psychology teachers are responsible for establishing mental health profiles of students, screening students for potential mental health problems, and identifying at-risk individuals for early intervention. Psychology teachers are recommended to attend training courses organized by the Shanghai Teacher Training Center, where they are trained and supervised by psychiatrists from the Medical Psychology Department of Shanghai Changzheng Hospital. The training includes Diagnostic and Statistical Manual of Mental Disorders (DSM-5), solution-focused brief therapy, family therapy and mindfulness, etc. If school teachers notice that a student shows some symptoms of psychological disorders such as anxiety or depression, they will refer the student to school psychology teachers who will assess his/her psychological level through interviews and assessment scales such as the Psychological Symptom Checklist (SCL-90). Based on interviews and case conceptualization, and also taking into account the results of the scales, school psychology teachers will offer intervention to students at risk of psychological trouble through a variety of approaches, including cognitive behavior therapy (CBT), mindfulness, social emotional learning (SEL), etc. CBT is used to alleviate anxiety, mindfulness for relaxation or self-regulation, and SEL to teach communication skills (Arora et al., 2019; Kirk et al., 2019). CBT and mindfulness training are conducted both individually and in groups, whereas SEL is mostly conducted in groups.

At the tertiary level, school psychology teachers refer high risk individuals to psychiatrists. Psychiatrists from the Medical Psychology Department of Shanghai Changzheng Hospital offer medical treatment and psychological therapy. School psychology teachers also offer psychological interventions in collaboration with psychiatrists and students' families.

During the outbreak of COVID-19, trained school psychology teachers worked quickly with psychiatrists to initiate effective actions. They carried out online mental health services which focused on at-risk individuals. They used a number of scales developed for measuring the impact of COVID-19 on mental health, for instance, the Fear of COVID-19 Scale (FCV-19S) (Ahorsu et al., 2020) and Coronavirus Anxiety Scale (CAS) (Lee, 2020), as screening scales. They developed a series of online Micro-Sessions on psychological wellbeing, and established a green channel for students with severe mental disorders to seek medical treatment. Trained school teachers popularized psychological and epidemic knowledge among students and caregivers to decrease public panic and mental health stress during the COVID-19 epidemic. These actions enabled teachers to help maintain and develop students' mental health in a timely manner. 
However, in face of the high demand for mental health care among students, caregivers, and teachers following the COVID-19 outbreak, the supply of professional psychological support in schools in China is insufficient. It is important to train a pool of qualified professional school psychology teachers through preservice teacher education. School psychology teachers need further training and mentoring in clinical psychology to quickly identify at-risk individuals in schools. Therefore, there is an urgent need for China to build a mental health promotion alliance mainly composed of educators and psychiatrists. We hope that education authorities would pay special attention to the development of applied clinical and counseling psychology disciplines and make it imperative to build effective referral channels in schools for medical interventions. Moreover, while carrying out the TTPSS, there is a need for systematic study of the implementation process of the mental health services on multiple levels: student level (e.g. mental health outcomes, satisfaction with services, etc.); parent outcomes (e.g. attitudes toward the services and changes in their children); teacher and school administration outcomes, etc. Such studies would inform both researchers and practitioners of potential issues in the implementation of the TTPSS with an eye to ensure its effectiveness.

Financial support. This study was funded by the National Social Science Foundation (17ZDA327) to YHB, and Shanghai Municipal Educational Science Research Program (C2-2020014) to LXW.

\section{References}

Ahorsu DK, Lin CY, Imani V, Saffari M, Griffiths MD and Pakpour AH. (2020) The fear of COVID-19 scale: development and initial validation. International Journal of Mental Health and Addiction 27, 1-9. doi: https://doi.org/10.1007/s11469-020-00270-8.

Alvarez AS, Pagani M and Meucci P (2012) The clinical application of the biopsychosocial model in mental health: a research critique. American Journal of Physical Medicine \& Rehabilitation 91, 173-180.

Arora PG, Collins TA, Dart EH, Hernandez S, Fetterman H and Doll B (2019) Multi-tiered systems of support for school-based mental health: a systematic review of depression interventions. School Mental Health: A Multidisciplinary Research and Practice Journal 11, 240-264.

Brooks SK, Webster RK, Smith L, Woodland L, Wessely S, Greenberg N and Rubin GJ (2020) The psychological impact of quarantine and how to reduce it: rapid review of the evidence. The Lancet 395, 912-920.

Chen Q, Liang M, Li Y, Guo J, Fei D, Wang L, He L, Sheng C, Cai Y, Li X, Wang J and Zhang Z (2020) Mental health care for medical staff in China during the COVID-19 outbreak. The Lancet. Psychiatry 7, e15-e16.

Duan L and Zhu G (2020) Psychological interventions for people affected by the COVID-19 epidemic. The Lancet. Psychiatry 7, 300-302.
Engel GL (1980) The clinical application of the biopsychosocial model. American Journal of Psychiatry 137, 535-544.

Fan F, Long K, Zhou Y, Zheng Y and Liu X (2015) Longitudinal trajectories of post-traumatic stress disorder symptoms among adolescents after the Wenchuan earthquake in China. Psychological Medicine 45, 2885-2896.

Guideline for psychological crisis intervention during 2019-nCoV (2020) National Health Commission of the People's Republic of China. Available at http://www.nhc.gov.cn/jkj/s3577/202001/6adc08b966594253b2b791be5c3b 9467.shtml (Accessed 27 January 2020) (in Chinese).

Guidelines for Psychological Assistance Hotline for the Prevention and Control of COVID-19-National Health Commission of the People's Republic of China. Available at http://www.nhc.gov.cn/jkj/s3577/202002/ f389f20cc1174b21b981ea2919beb8b0.shtml (Accessed 7 February 2020) [in Chinese].

Kirk A, Michael KD, Bergman SM, Schorr M and Jameson JP (2019) Dose response effects of cognitive-behavioral therapy in a school mental health program. Cognitive Behaviour Therapy 48, 497-516.

Lee SA (2020) Coronavirus Anxiety Scale: a brief mental health screener for COVID-19 related anxiety. Death Studies 44, 393-401.

Liem A, Wang C, Wariyanti Y, Latkin CA and Hall BJ (2020) The neglected health of international migrant workers in the COVID-19 epidemic. The Lancet. Psychiatry 7, e20.

Liu S, Yang L, Zhang C, Xiang Y-T, Liu Z, Hu S and Zhang B (2020) Online mental health services in China during the COVID-19 outbreak. The Lancet. Psychiatry 7, e17-e18.

Main A, Zhou Q, Ma Y, Luecken LJ and Liu X (2011) Relations of SARS-related stressors and coping to Chinese college students' psychological adjustment during the 2003 Beijing SARS epidemic. Journal of Counseling Psychology 58, 410-423.

Mura G, Vellante M, Nardi AE, Machado S and Carta MG (2015) Effects of school-based physical activity interventions on cognition and academic achievement: a systematic review. CNS \& Neurological Disorders Drug Targets 14, 1194-1208.

Oberle E, Guhn M, Gadermann AM, Thomson K and Schonert-Reichl KA (2018) Positive mental health and supportive school environments: a population-level longitudinal study of dispositional optimism and school relationships in early adolescence. Social Science and Medicine 214, 154-161.

Primary, secondary and tertiary prevention-Institute for Work \& Health (2015) Available at http://www.iwh.on.ca/Primary-secondary-and-tertiaryprevention. Published April 2015.

Read J, Fink PJ, Rudegeair T, Felitti VJ and Whitfield CL (2008) Child maltreatment and psychosis: a return to a genuinely integrated bio-psycho-social model. Clinical Schizophrenia \& Related Psychoses 2, 235-254.

Wang G, Zhang Y, Zhao J, Zhang J and Jiang F (2020) Mitigate the effects of home confinement on children during the COVID-19 outbreak. The Lancet 395, 945-947.

Yang Y, Li W, Zhang Q, Zhang L, Cheung T and Xiang Y-T (2020) Mental health services for older adults in China during the COVID-19 outbreak. The Lancet. Psychiatry 7, e19. 